\title{
Re- Processing of 2D Seismic Line APH-434- The Alpha Basin, Offshore, New Zealand.
}

\author{
Fredrick OgochukwuOkocha, M.Sc. \\ Department of Physics, Delta State University, Abraka.
}

\begin{abstract}
A set of 2-D seismic reflection data from New Zealand was used as a part of this seismic processing procedure. It was known that, at this region a set of petroliferous reservoir situated in an anastomosing faults were present. The objective of this seismic processing is to create an image of the substructure beneath a fault zone known as the Alpha fault zone. The processing involves in removing refractions and direct arrivals, applying true amplitude recovery; correction to account for seismic energy decay and applying a noise filter to remove the random noise recorded whilst data acquisition. At the preliminary stage, a filtered unstacked seismic data was obtained. It is clear that more advanced processing of the seismic data needs to be done to improve the signal-to-noise ratio of the seismic data. In the final processing sequence (migration) an accurate velocity field is obtained for generating the subsurface image. Dip Move out (DMO) and post-stack time migration are the processes which were applied to the APH-434 dataset. A processing workflow has been outlined in this report for future testing and signal analysis of the seismic data.
\end{abstract}

(Keywords:2-D seismic reflection data,seismic processing, signal-to-noise, Alpha fault)

\section{Introduction}

The area of study is located in the Alpha basin, the coast of New Zealand as shown in Figure 1. The seismic data was used for investigation of hydrocarbons by the New Zealand Oil and Gas Company (NZOG). The 2D Seismic dataset (Line APH-434) was acquired by Norpac International crew. The dataset was acquired from west to east to cover the main fault zone which is called the Alpha fault. The exploration concepts in the basin relate to an anticlinal-structural trap and a tilting fault block formed during the thrusting period. An overview of the geology, the data processing strategy and the summary of seismic dataset are given in the subsequent sections.

\section{Geological Overview}

The Alpha basin is located in the offshore south western part of the North Island, New Zealand. The eastern part of the basin is bounded by the Alpha fault zone which is a part of the large NE-SW thrust fault system (Holt, 2004) as shown in Figure 1. The potential of hydrocarbon accumulations was investigated in the basin by using several types of data such as seismic data, gravity data and well data. Moreover, the evolution of the Alpha basin was studied to understand tectonics history that might increase possibility of success. The main tectonic events started from the Late Cretaceous to the Paleocene that associated to the extensional regime (Nicol et al., 2004), the Alpha fault was also active during this period. In the early Miocene, the maximum regional subsidence stage occurred. The subsidence extended eastward and seawater occupied the western part of the basin to a depth of 1-1.5 km. In the eastern part, rock in the thrust zone was compressed and exposed to the surface as a result of erosion. In addition, the thickness of the Australian crust increased approximately 1.5 $\mathrm{km}$ in the subduction zone, this thickening was associated with topographic build up. Therefore, the thrust front was heavily eroded in the areas that were above sea level. For this reason, large amount of eroded sediment was transported westward to the foreland basin. Fault displacements resulted in westward motion and pushed the eastern hangingwall block overly on the western footwall from the Pliocene to present time as shown in Figure 2 


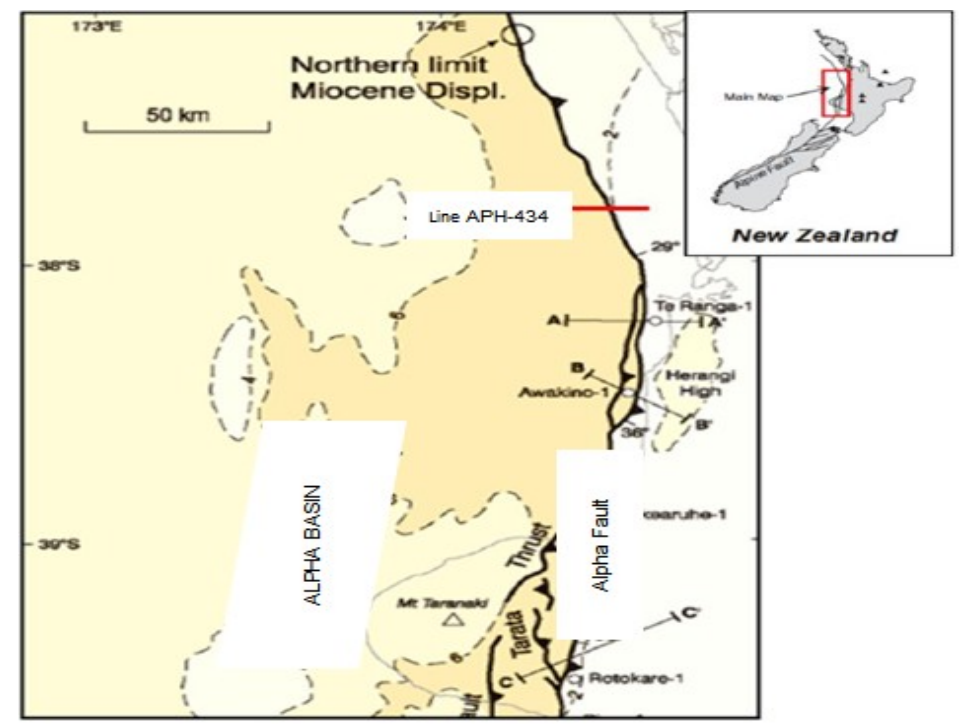

Figure 1:Location of the seismic line (red) APH-434 and its relation to the surrounding structural elements, particularly the Alpha fault (Nicol et al., 2004)

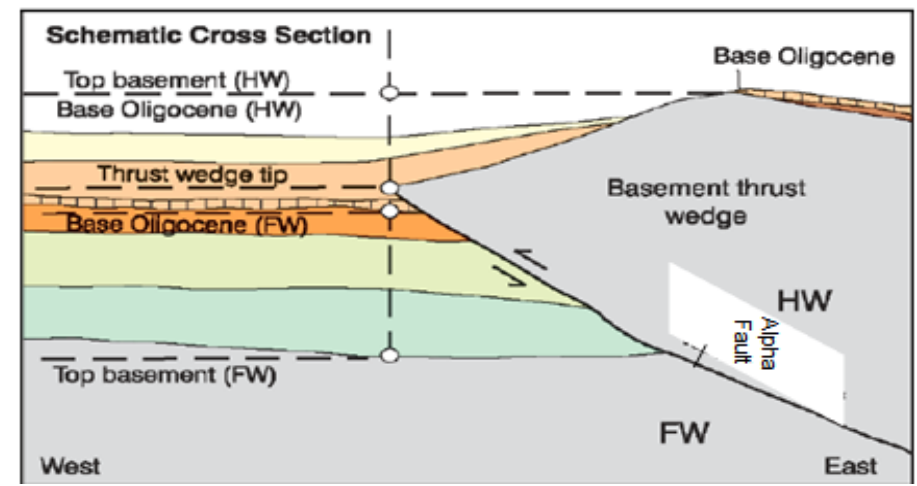

Figure 2: General thrust geometry cross-section of the Alpha fault. The Mesozoic basement rock thrust over the Cretaceous and the Tertiary rock in the western part (Nicol et al., 2004).

In terms of the petroleum system, the source rocks were mainly formed from the Cretaceous organicrich sediments of the Rakopi formation, the Paleocene marine mudstone and the coal-bearing Eocene beds. The Oligocene and the Eocene sandstone are the main reservoirs in the Alpha basin. The Oligocene shale, the Eocene and the Miocene mudstone are the cap rocks. Hydrocarbons tend to move eastward and are trapped at high points in the reservoir beneath the low permeability of the fault surface (Nicol et al., 2004). Thus, understanding the fault geometries and their mechanisms is the key to success in hydrocarbon exploration. In the Alpha basin, poor seismic images are unable to be resolved by using the conventional time migration process; this is owing to the facts that lateral velocity changes from low velocity (younger sediments) to high velocity (basement) moving east to west. These changes affect the seismic ray paths which generate non-hyperbolic move out in CMP domain. Therefore, pre-stack timemigration was applied to the APH-434 dataset to improve the geological structures that were below the Alpha fault as shown in Figure 3. Improvements in seismic data processing can assist the interpreters to gain more geological knowledge of the area.

\section{Objectives of Data Re-Processing}

The Alpha fault play a major role in the petroleum system of the Alpha basin, it is important that the seismic image may be displayed properly. Consequently, reprocessed seismic image may help in a better delimitation of the stratigraphic and structural traps related to the Alpha fault. We may also be interested in a better seismic expression of the basement interval, providing better quality sections for interpretation through high frequency preservation, effective multiple removal and preservation of amplitudes. The time zone of interest is between 1 and 4 seconds. The development of an appropriate data processing scheme and its application is covered in the other sections of the report. 


\section{Acqusition Configuration And Dataset Characteristics}

The seismic line APH-434 was acquired perpendicular to the Alpha fault zone by Norpac International crew in 1986. The total length of the line is $22.7 \mathrm{~km}$ started from west to east of the west coast, New Zealand. The diagram of this marine acquisition configuration is displayed in Figure 4. The summary of acquisition parameters is shown in Table 1

\begin{tabular}{|c|c|}
\hline \multicolumn{2}{|c|}{ Dataset information } \\
\hline Area/Block/Coountry & Offshore/ New Zealand \\
\hline Year of acquisition & 1986 \\
\hline Sunvey Type & $2 \mathrm{D}$ \\
\hline Terrain & offshore/ Marine \\
\hline Sunvey configuration & off-end \\
\hline Energy source & single airgun array \\
\hline Fold coverage & 60 \\
\hline Bin size $(m)$ & $12.5 \mathrm{~m}$ \\
\hline Near offset (m) & 258 \\
\hline Far offset (m) & 3,233 \\
\hline Line length $(\mathrm{km})$ & $22.7 \mathrm{~km}$ \\
\hline \multicolumn{2}{|c|}{ Recording inforamation } \\
\hline Recording system & DFS-V \\
\hline Data format & SEGD 3480 cartidges \\
\hline Recording length (s) & $6 \operatorname{secs}$ \\
\hline Sampling rate (ms) & $2 \mathrm{~ms}$ \\
\hline \multicolumn{2}{|c|}{ Source information } \\
\hline Shot point interval (m) & $25 \mathrm{~m}$ \\
\hline Shooing direcction (Azimuth) & 90 \\
\hline Total number of SP/ FFID & $876 / 100-975$ \\
\hline Gun depth & $6 \mathrm{~m}$ \\
\hline \multicolumn{2}{|c|}{ Receiver information } \\
\hline Receiver group interval (m) & $25 \mathrm{~m}$ \\
\hline Number of receivers/ streamer & 120 \\
\hline Receiver depth & $13 \mathrm{~m}$ \\
\hline
\end{tabular}

Table 1: Summary of the acquisition parameters of the line APH-434 (GNS, 2009)

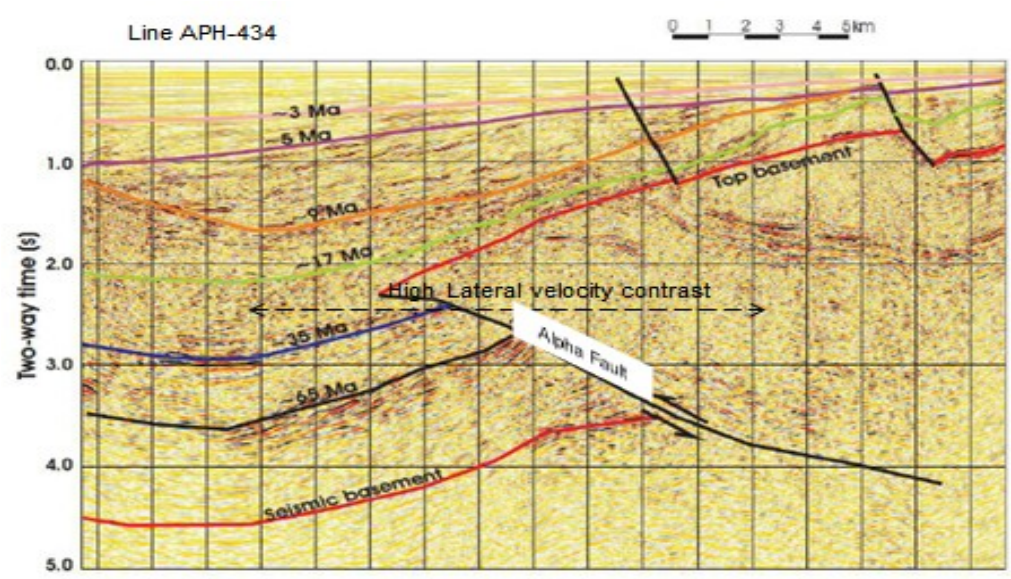

Figure 3: The 2D seismic line APH-434 before reprocessing with a first geological interpretation 


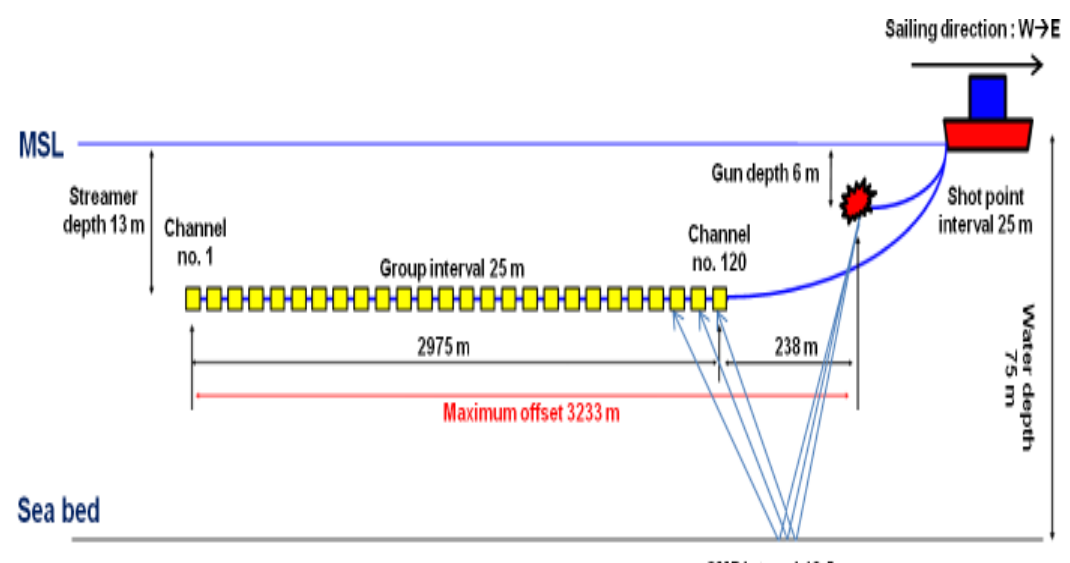

CMPinterval $12.5 \mathrm{~m}$

Figure 4: Seismic acquisition configuration of the line APH-434

\section{Methodology}

The order of processing sequence is data dependent and should be adjusted to meet project objectives and to solve any specific geophysical problems in survey area. The sequence in this work was adapted from the Globe Claritas software processing tutorial as shown in Figure 5. Regarding to time constrain, the adapted flow was not as good as modern industry standard. There were many steps that were not added into processing flow such as De-signature, Q-compensation and pre-stack time migration. However, the processing flow consists of DMO (Dip Move Out) and post-stack migration which is theoretically identical with pre-stack time migration flow (Russell, 1998). Note that this only stands if the velocity field is well constrained. From this point of view, velocity analysis is a crucial step for generating a reliable the subsurface image. Therefore, getting a comparable result with pre-stack time migration is very challenging for this work.

\section{Pre-Processing And Noise Attenuation}

The first stage of the pre-processing stage involves the removal of refractions and direct arrivals. The front mute was picked in the shot record no.300 in order to remove refractions and direct arrivals. The seismic data that are above the front mute are classified as unwanted energy as shown in Figure 6. Thus, the amplitudes above the mute were eliminated by multiplication with zero. This process was done to prevent taking the nonreflection energy into account of amplitude decay analysis. Figure $7 \mathrm{a}$ and $7 \mathrm{~b}$ show the shot records before and after muting respectively

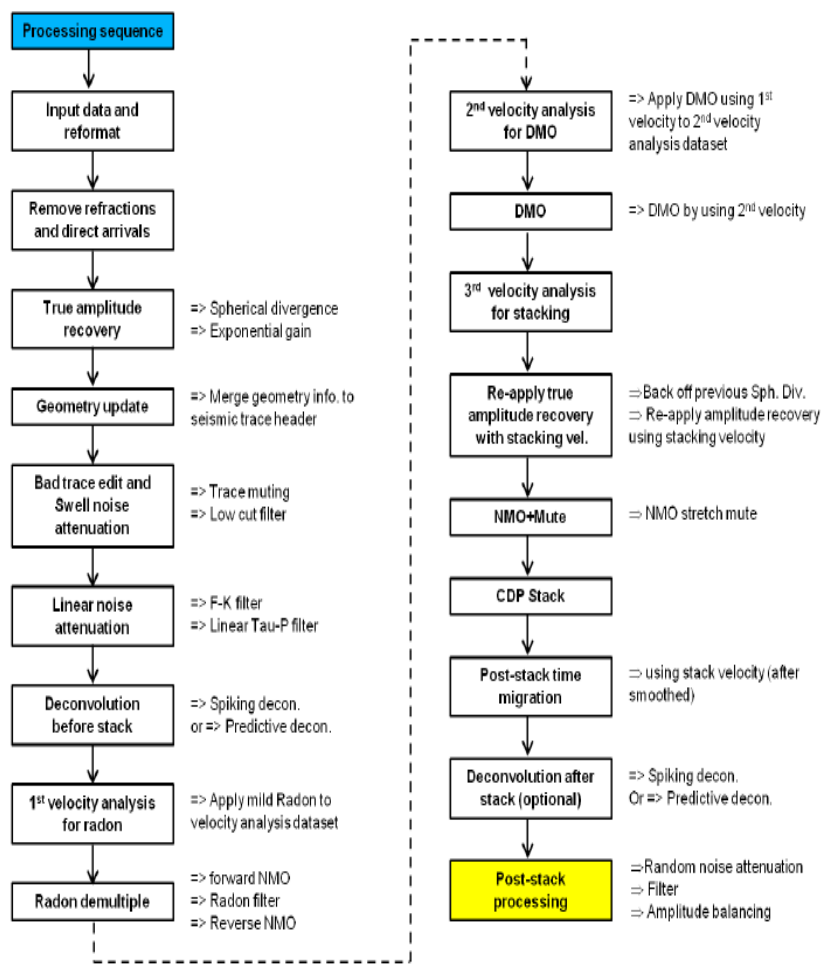

Figure 5:The summary of processing sequence applied to the APH-434 seismic dataset 


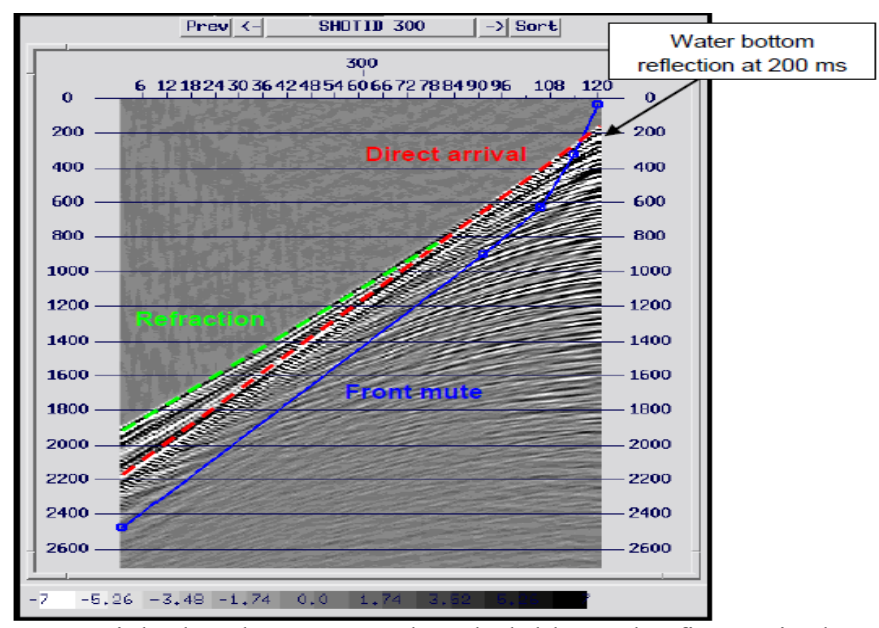

Figure 6:The front mute was picked and represented as dark blue. The first arrivals propagated through water with $1,500 \mathrm{~m} / \mathrm{s}$ to hydrophones as displayed in red dash line. The refractions represented as light green.

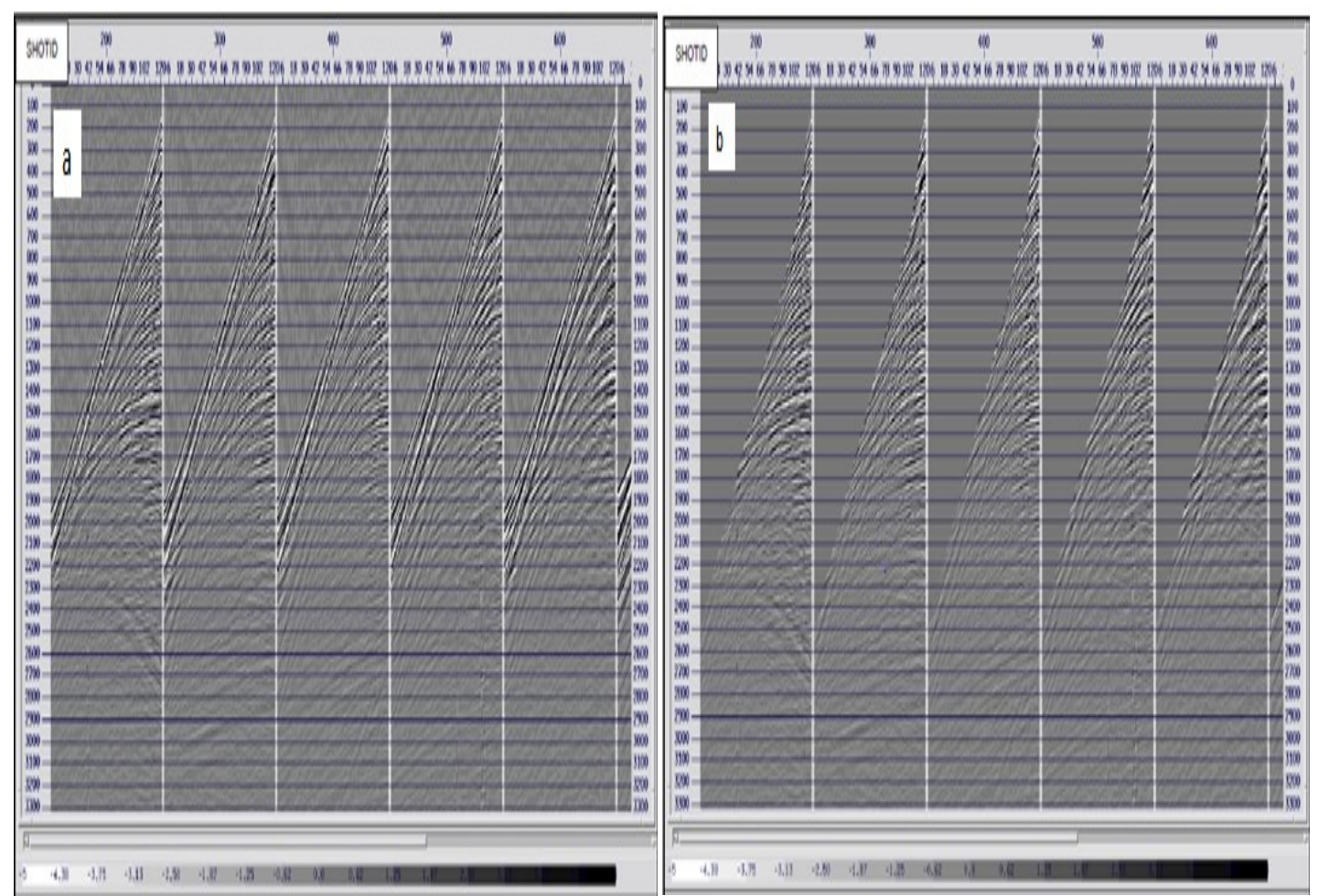

Figure 7: (a) The raw shot records without the front mute applied (b) The raw shot records with the front mute applied.

\section{True Amplitude Recovery}

True amplitude recovery process is the deterministic amplitude correction that is normally used to compensate the spherical divergence phenomenon and attenuation of seismic waves (Gadallah and Fisher, 2005). Shot points display before and after it is applied are shown in Figures $8 \mathrm{a}$ and $8 \mathrm{~b}$. The amplitude decay curve in the raw shot records clearly display the effect of spherical divergence phenomenon and attenuation which represented as amplitude decreasing with increasing time, shown in Figure 8a. After evaluating the testing results, the spherical divergence correction $\left(\mathrm{TV}^{2}\right)$ combined with exponential gain $(1 \mathrm{~dB} / \mathrm{sec})$ provide a good balance of amplitudes in both shot records and the amplitude decay curve as shown in Figure $8 \mathrm{~b}$. Therefore, these parameters were applied to the whole dataset. 

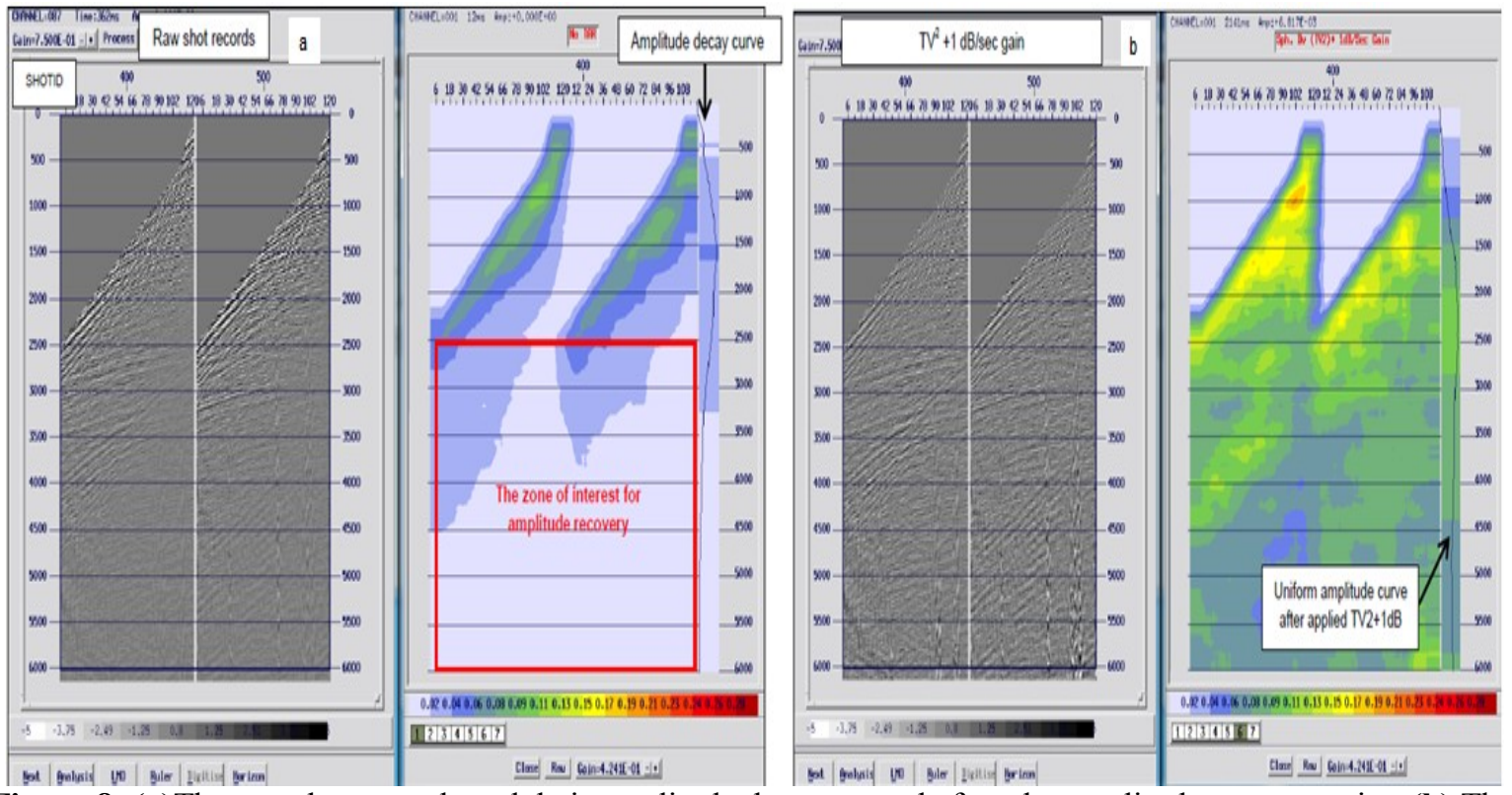

Figure 8: (a)The raw shot records and their amplitude decay curve before the amplitude compensation (b) The raw shot records after Spherical divergence correction $\left(\mathrm{TV}^{2}\right)+1 \mathrm{~dB} / \mathrm{sec}$ gain

\section{Swell Noise Attenuation}

Swell noise is generated by sea wave. The levels of the noise depend on weather conditions during acquisition period. The seismic shot records contaminated with swell noise are shown in Figure 9. The characteristic of swell noise are low frequency and high amplitude. The method for swell noise attenuation is by using a Low cut filter (High-pass filter). The consideration for using low filter is to attenuate the swell noise in the dataset as much as possible and preserve primary data as well. For this reason, a set of low cut filter parameters was tested to optimize the best filter. Moreover, the difference plots generated by subtracting the original data with filtered data are used to justify the final parameter of the tests. In Figure 10, the low cut filter was unable to attack the swell noise that contains higher frequency than $5 \mathrm{~Hz}$. This is due to the fact that the frequency range of noise and data are the same range. In the difference plot, both noise and data are removed by the filter. Therefore, $5 \mathrm{~Hz}$ of low cut filter should be enough to remove swell noise at this level.

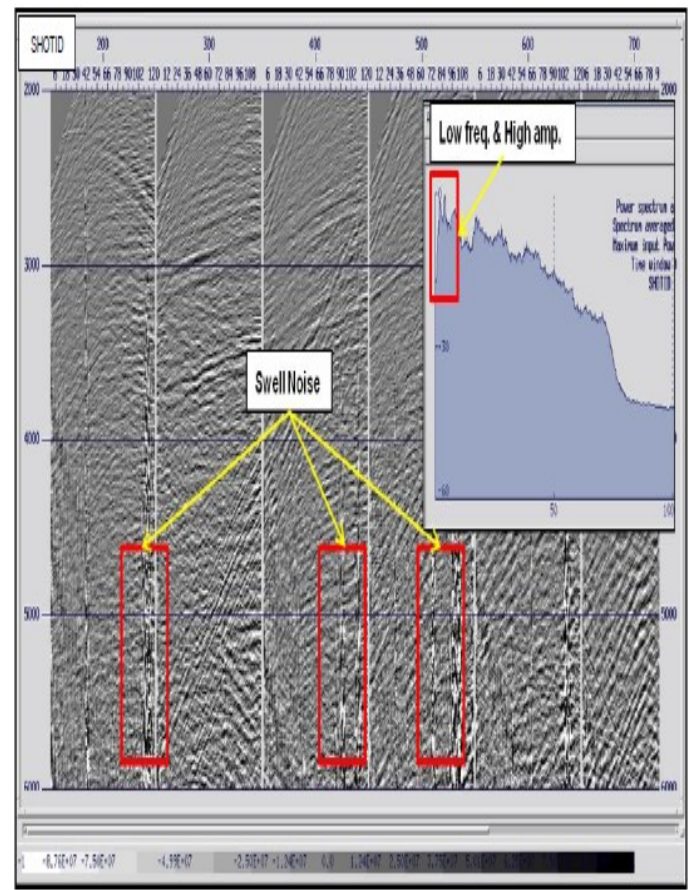

Figure 9:The swell noise represented inside the red boxes. It's obvious in the frequency spectrum that the noise behaviour is high amplitude and low frequency content. 


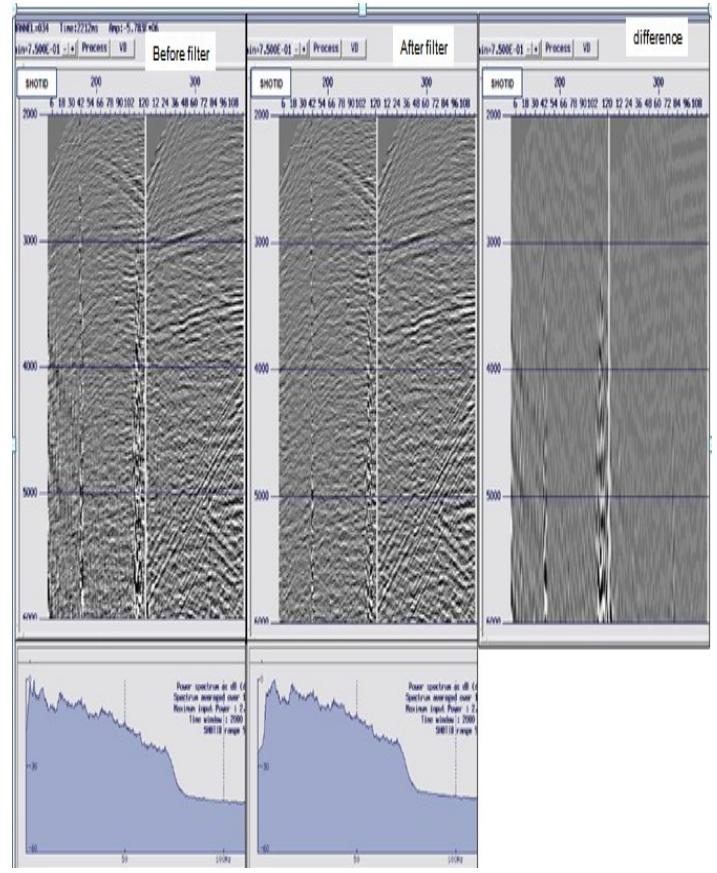

Figure 10:5Hz of the Butterworth low cut filter was selected. The low frequency noise such as swell noise and the noise generated by tail buoy were removed as displayed in the difference plot

\section{Minimum Phase Conversion andDeconvolution}

The deterministic phase conversion for this processing is usually called the system delay correction. This system delay is able to observe in the near trace display as shown in Figure 11. Based on the acquisition geometry, the first arrival and the sea bed reflection time should be recorded by the nearest channel (channel no. $120)$ at $158.7 \mathrm{~ms}$ and $181.5 \mathrm{~ms}$ respectively. The observations of near traces display shows that the time delay between the calculations and the data is approximately $18 \mathrm{~ms}$. In order to perform the correction, a recorded source signature is used to correct the system time delay. The concept of the correction is to determine the matching filter which is able to shift the source signature to start at zero time. The procedure to determine the matching filter is shown in Figure 12. To verify the effect of minimum phase filter, the original source signature was convolved with the filter as result of D. If the result is similar to the minimum phase source signature, then the filter is valid and able to convolve with the real seismic dataset.

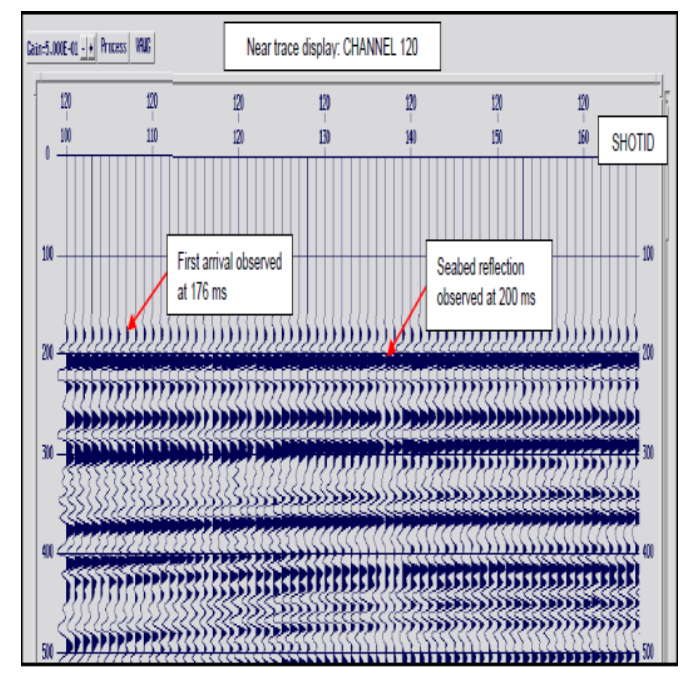

Figure 11:The near trace display of channel no. 120 can be used to check whether there is any time delay in the data. Comparing the arrival time between the calculation and data, it is possible to approximate the system time delay. 


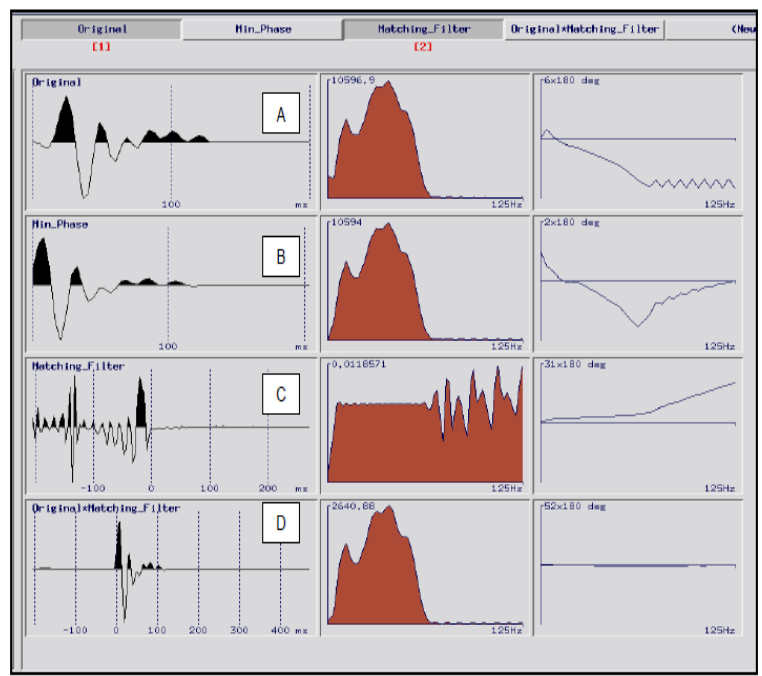

Figure 12: The original source signature represented as A. The minimum phase signature represented as B. The matching filter $(\mathrm{C}$, minimum phase filter) is determined from these two inputs. The convolution result between the original signature and the minimum phase filter is identical with the minimum phase signature $(D=B)$

After deriving the minimum phase filter, the filter was convolved with the seismic dataset with an upward shift of $19 \mathrm{~ms}$ as shown in Figure 13. Finally, the time of sea bed reflection and the first arrival correspond to the times calculated by using the geometry information.

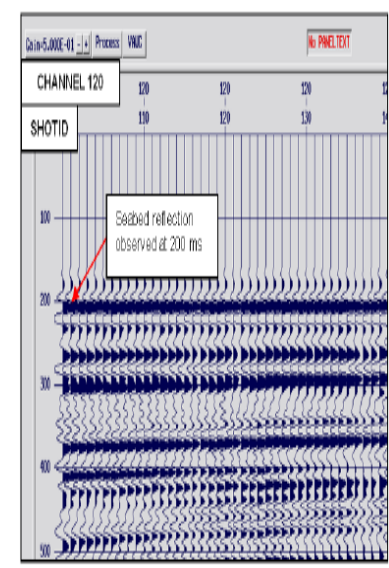

The original data

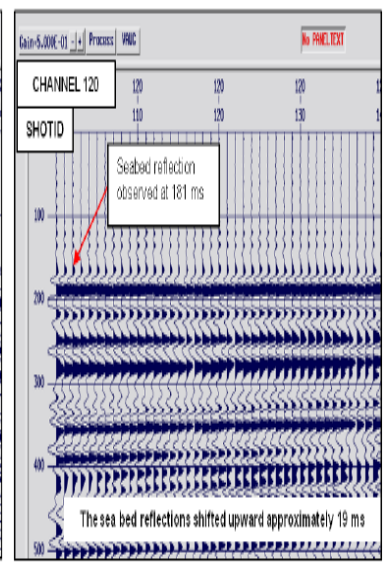

The result atter minimum phase conversion

Figure 13: The near trace displays show comparison between before and after minimum phase conversion

\section{Deconvolution}

Deconvolution is generally the inverse process of the convolutional model between the earth reflectivity and the seismic source wavelet as shown in Figure 14. The main purpose of the process is to recover the earth reflectivity in the seismic traces by compressing the seismic source wavelet to higher temporal resolution or spike (Yilmaz, 2005). Those reflectivity series present the geological layers in the subsurface.

Two types of deconvolution methods are widely used in industry; the spiking and the predictive deconvolution. Firstly, the spiking deconvolution method shapes the wavelet to a spike to represent the reflectivity of the subsurface. In some cases, this deconvolution method provides an unstable result. This is owing to noise and the source wavelets are unknown. For this reason, the predictive deconvolution method is introduced to attenuate only the periodic part of seismic traces such as multiple and reverberation energy. The two methods of deconvolution are based on the least-square method. However the predictive deconvolution is based on the optimum Weiner filter, which is mainly used to improve the resolution in the seismic data (Yilmaz, 2005). The process is generally applied to the minimum phase pre-stack dataset. 


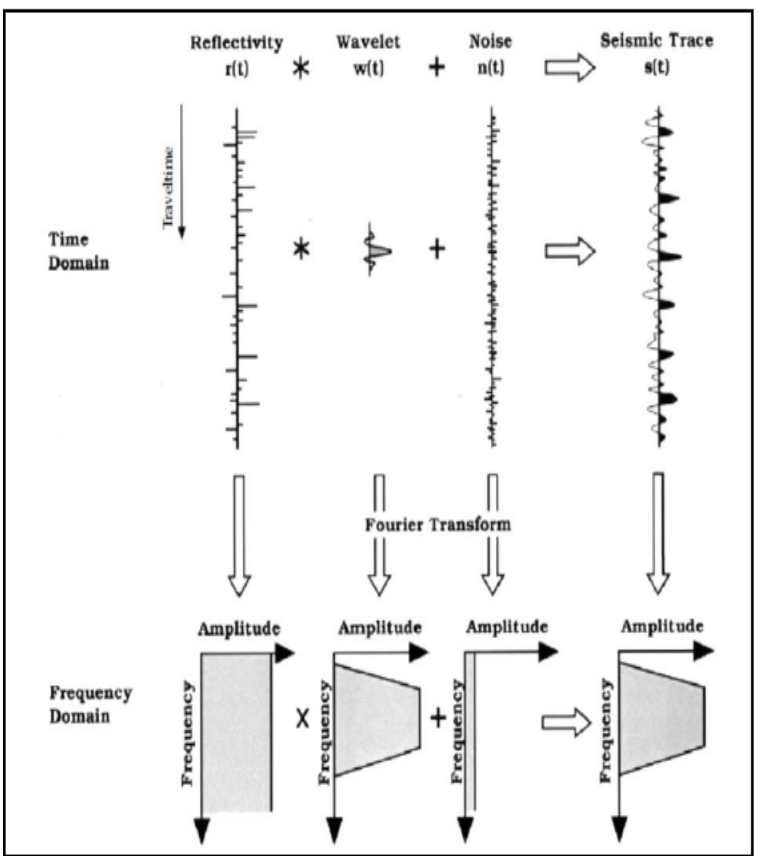

Figure 14:The convolutional model to illustrate how to generate seismic traces (Hatton et al.,, 1986)

Based on the assumption that the autocorrelation function is represented by the shape of wavelet in seismic data (Yilmaz, 2005), thus, the way on how to design the predictive deconvolution filter is simplified as shown in Figure 15

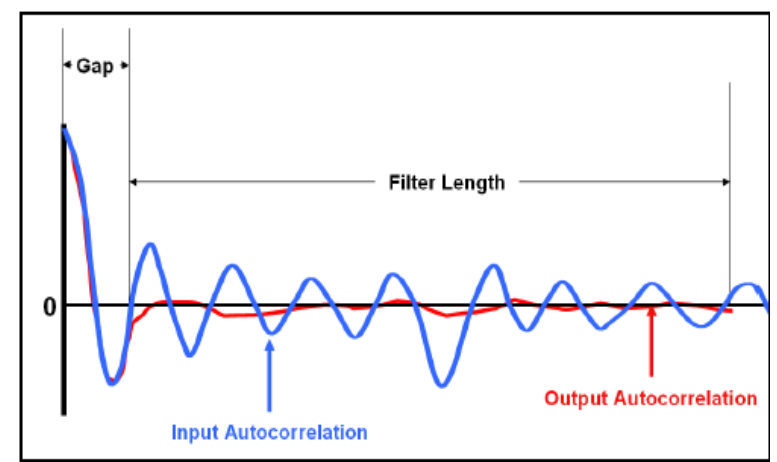

Figure 15:Gap length should be appropriate to get the highest temporal resolution for each particular dataset. The filter length should be long enough to cover the multiple or reverberation energy.

The evaluation of deconvolution was based on the autocorrelation function and the data. The $240 \mathrm{~ms}$ operator length effectively attenuated the multiple as shown in Figure 16. Also, the longer operator length performed a good attenuation as well. However, the $240 \mathrm{~ms}$ operator length was selected to avoid any damage to the data. The second parameter is gap length; $24 \mathrm{~ms}$ gap length provides a good shape of the autocorrelation function. Furthermore, the consistency of the wavelet from $24 \mathrm{~ms}$ gap is high as shown in Figure 17b when compared to Figure 17a 

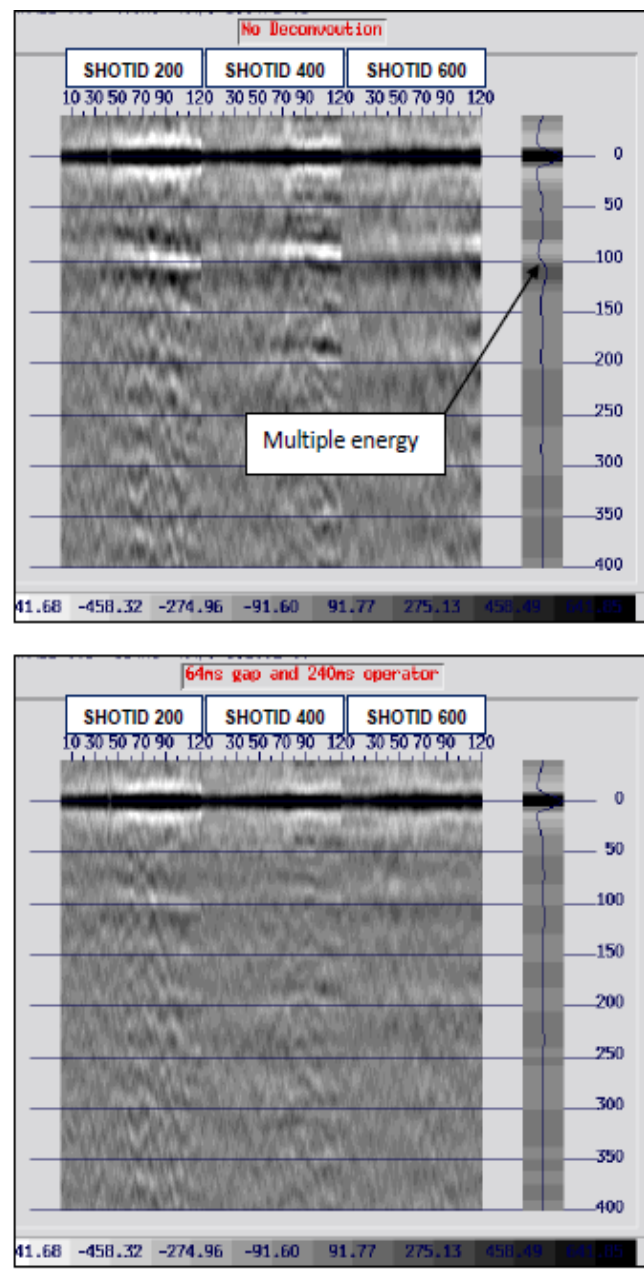

Figure 16: The autocorrelation function

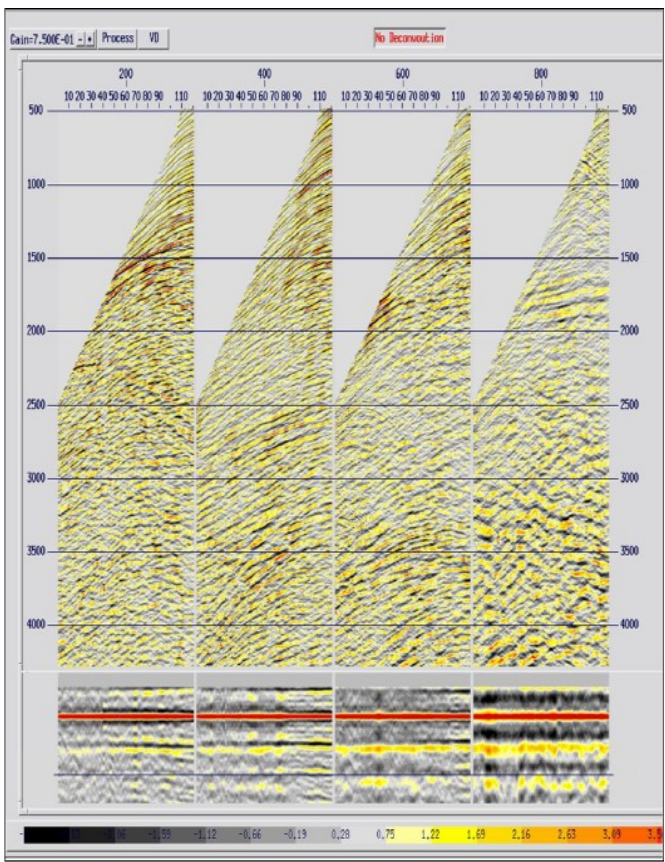

Figure 17a: Before the Deconvolution 


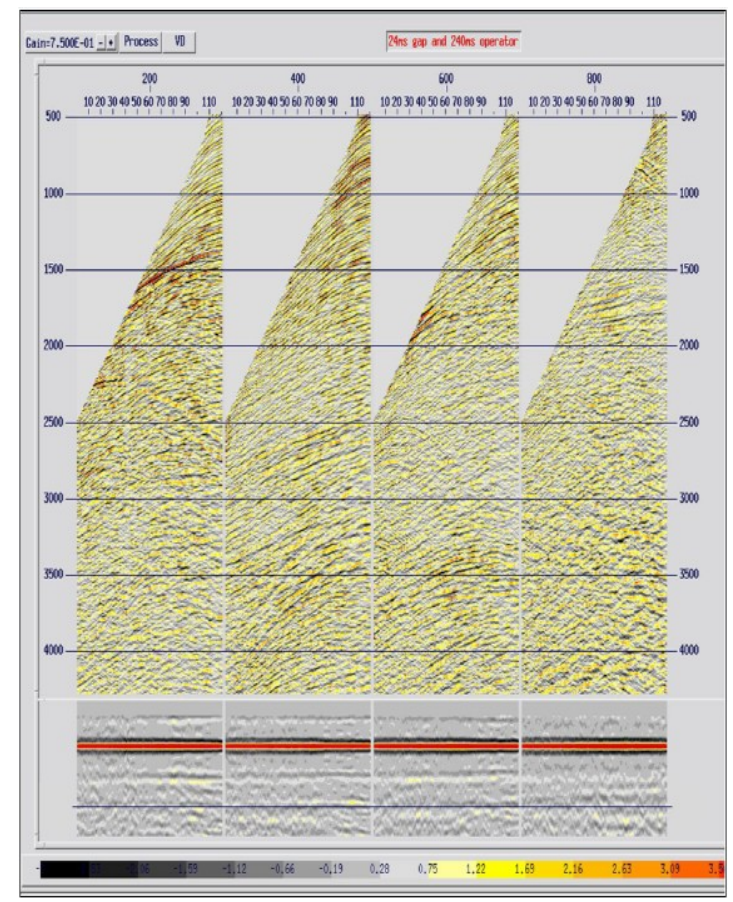

Figure 17b:After 24 ms Gap 240ms Op. Length Deconvolution

\section{Velocity Analysis}

The purpose of velocity analysis is to determine the velocity fields for NMO correction. These velocity functions are used to flatten the primary reflections in CDP gather for giving the optimum stack. If applying NMO correction with wrong velocity, the primary reflection cannot be flat and then will affect the quality of stack section.

The velocity analysis tools used to determine the NMO velocity includes the velocity semblance, CDP gathers, and stack section as shown in Figure 18. One of the key considerations of velocity analysis depends on the data conditions and the number of velocity pickings to obtain the right velocity model. The processing workflow is associated with three velocity picking.

The $1^{\text {st }}$ velocity picking is for demultiple point of view. This picking is to flatten the primary reflection as a result of under correction of the multiples in CDP gather. The different moveouts will be transformed to the different location in parabolic Tau-P domain. It is very important thing to emphasize that using too high velocity for the Radon demultiple will eliminate both the primaries and multiples. To avoid any damage to the primary reflections, slightly picking the slow velocity trend is recommended.

In the $2^{\text {nd }}$ velocity picking, the DMO velocity is picked based on the initial DMO corrected data using the $1^{\text {st }}$ velocity. Thus, the second velocity is based on assumption that there is no dipping effect in the CDP gather. The velocity semblance provides the actual velocity trend compared with the first velocity picking.

In the $3^{\text {rd }}$ velocity picking, the stacking velocity is determined after applying the DMO to the dataset using the second velocity. The strategy for this picking is to flatten the CDP gathers as much as possible to produce a good stack section. 


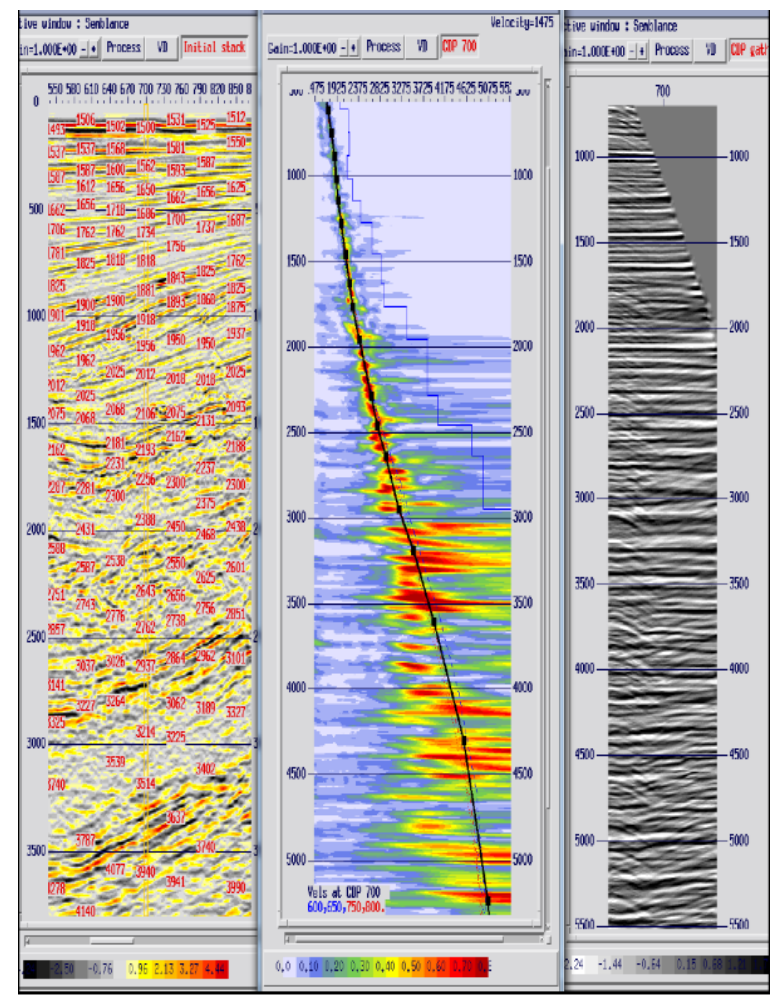

Figure 18: The three panels used for velocity analysis. The left panel is the stack section overlay with velocity point at picking location. The middle panel is the velocity semblance;it's useful to determine the velocity trend at particular CDP location. The right panel is the CDP gather after applying NMO correction using picking velocity.

The Figure 19 shows the velocity semblance from different stages of velocity picking. The semblances are improved after radon and DMO. The semblance after radon demultiple is approximately multiple free. Thus, the velocity trend should not be complicated to pick. At the end of velocity analysis, the velocity trend after DMO should be the best stacking velocity.

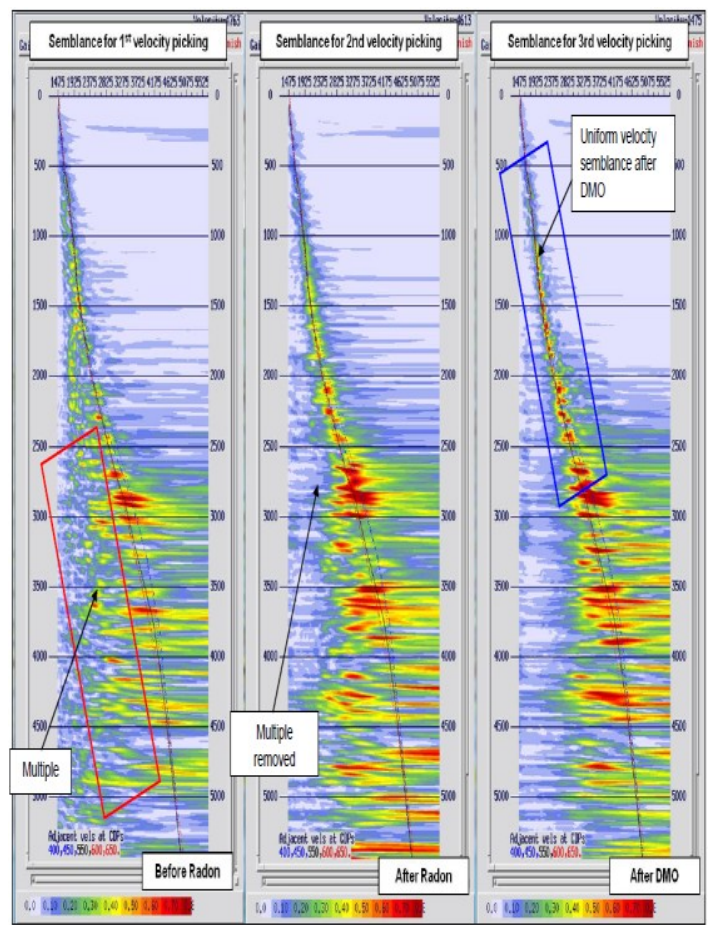

Figure 19: The velocity semblance of different stages in the processing sequence. 


\section{Normal Moveout Correction}

The basic principle of NMO correction is to flatten reflections which are represented as the hyperbola in CDP gather as shown in Figure 20. In the other words, the NMO correction converts the non-zero offset data to the zero offset data using offset and velocity information. . After the correction, the seismic reflections ray paths are assumed to be a vertical incident ray path. In dipping layers cases, DMO or pre-stack time migration is needed to remove the dipping effect before stacking. Finally, the NMO correction is necessary for stacking process.

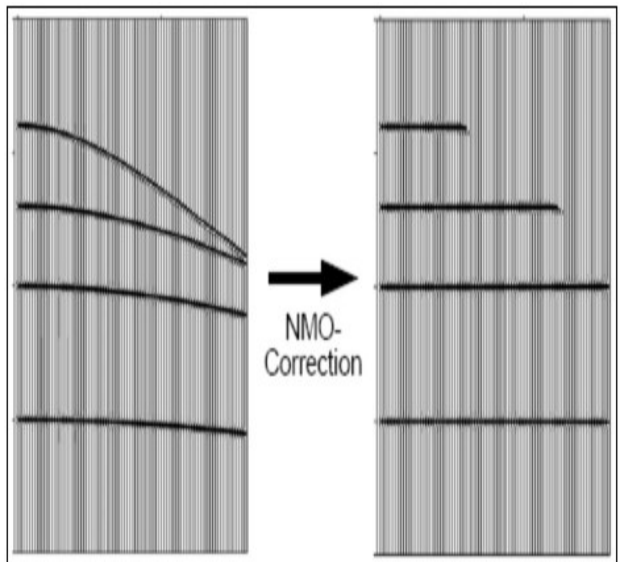

Figure 20: The CDP gather before and after applying NMO correction. The gather is changed from the nonzero offset to zero offset data by this correction. (Yilmaz, 2005)

\section{Migration}

Migration process is moving apparent seismic dipping events to their actual subsurface locations (Yilmaz, 2005). A seismic section is assumed to represent a cross-section of the earth. The assumption works best when layers are flat, and fairly well when they have gentle dips. In case of steeper dip, the assumption breaks down. This is due to that the reflections are located in the wrong places in both horizontal and vertical location as shown in Figure 21. Dipping reflector such as a valley and point reflector are the problems that break the assumption as stated above. Based on the Figure 21, risk of structural interpretations is relatively high if unmigrated seismic section is used for structural interpretation. In the migration process, an accurate velocity field is required for generating the subsurface image. As a result of delineating subsurface details such as fault planes and collapsing diffractions.

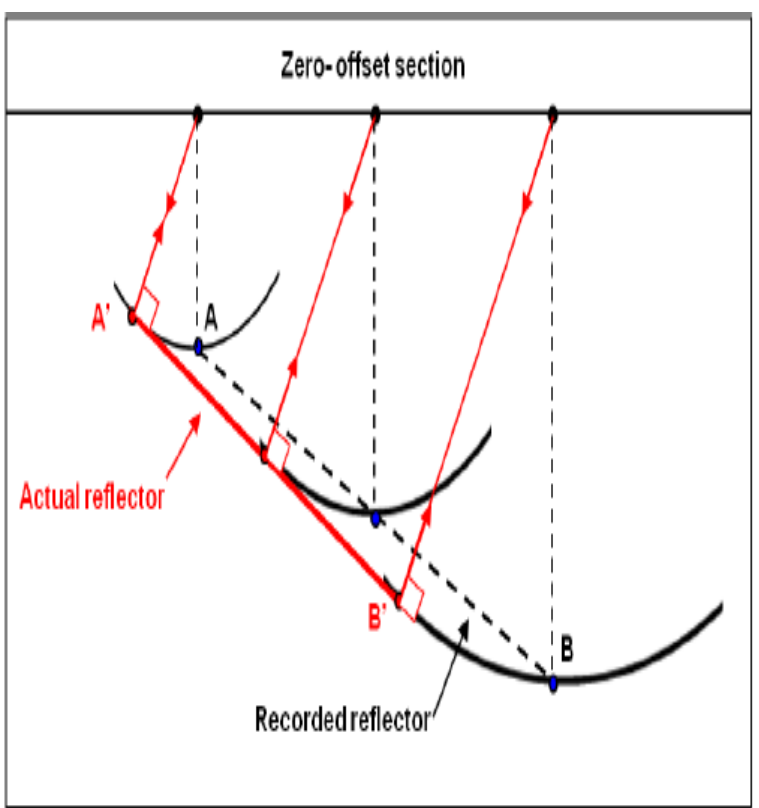

Figure 21:Migration (post-stack) moves the recorded reflector (AB) to the actual position (A'B'). at A and B locations, the reflectors are moved along the semi-circle to $\mathrm{A}^{\prime}$ and $\mathrm{B}^{\prime}$. After the migration, the length of dipping reflector is shortening. Moreover, the slope of dipping event is also increased after migration. 
In the migration processes for line APH-434, the most important input parameter is the migration velocity as shown in Figure 22. Sometimes, the velocity is too low or too high. Therefore, the velocity scaling was performed to determine the best migration image. After migration, diffractions, fault planes and dipping event should be relocated to their actual subsurface locations. In addition, different migration algorithms also provide different migration results. Thus, the post-stack finite difference migration, the post-stack Kirchhoff migration and the pre-stack Kirchhoff migration were performed to determine the best migration method.

The velocity scaling tests were performed by using the post-stack finite difference migration. From the test results in Figure 23, the fault plane reflections and diffractions were handled properly by $110 \%$ of input velocity. In contrast, the input velocity produced the under-migrated image. Finally, the scaling $110 \%$ was used to conduct the final migrated section as shown in Figure 25.

The comparison of the three migration algorithms are shown in Figure 24. The post-stack Kirchhoff time migration provided the best imaging result such as high sharpness of fault plane. This migration generated the migration artifact less than the post-stack finite difference migration. Furthermore, the post-stack Kirchhoff time migration result was identical with the pre-stack Kirchhoff time migration; this is due to the fact that the thrust features generate high lateral velocity contrast in the area. Thus, the time migration method is unable to solve ray bending effects in this area. Finally, post-stack Kirchhoff time migration was selected to produce a migrated section for the Alpha Basin dataset as shown in Figure 25

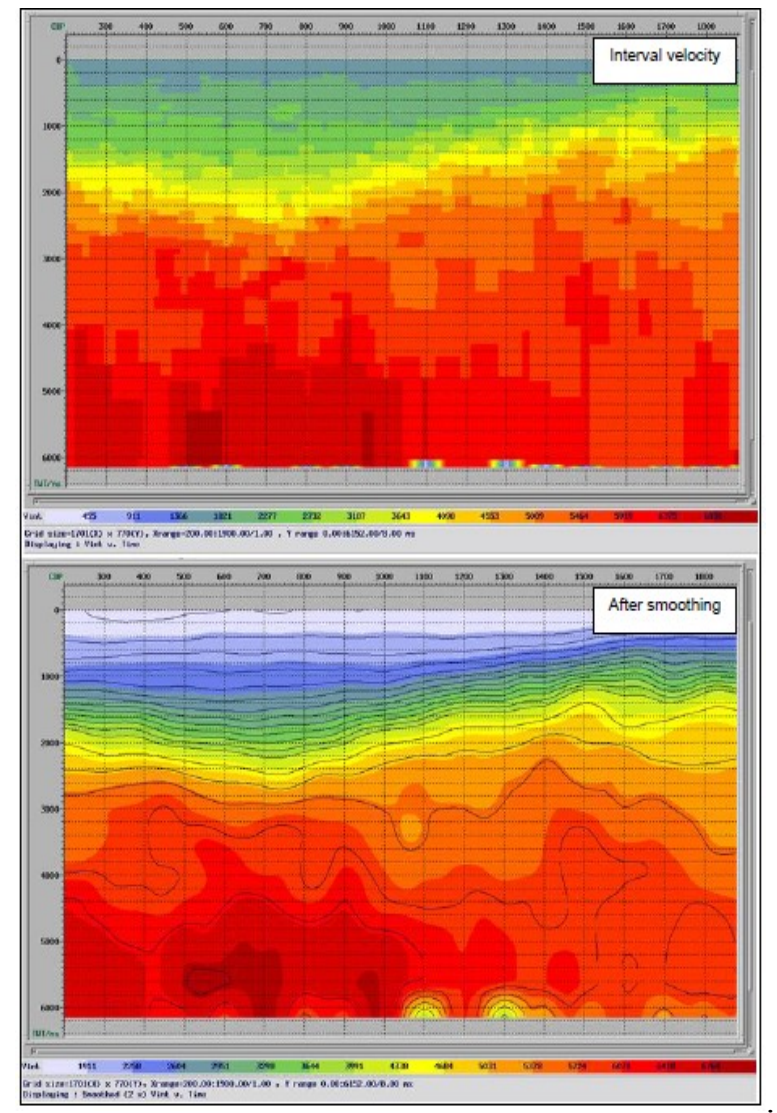

Figure 22: The smoothed (lower) version of migration velocity generated by the interval velocity (upper) 


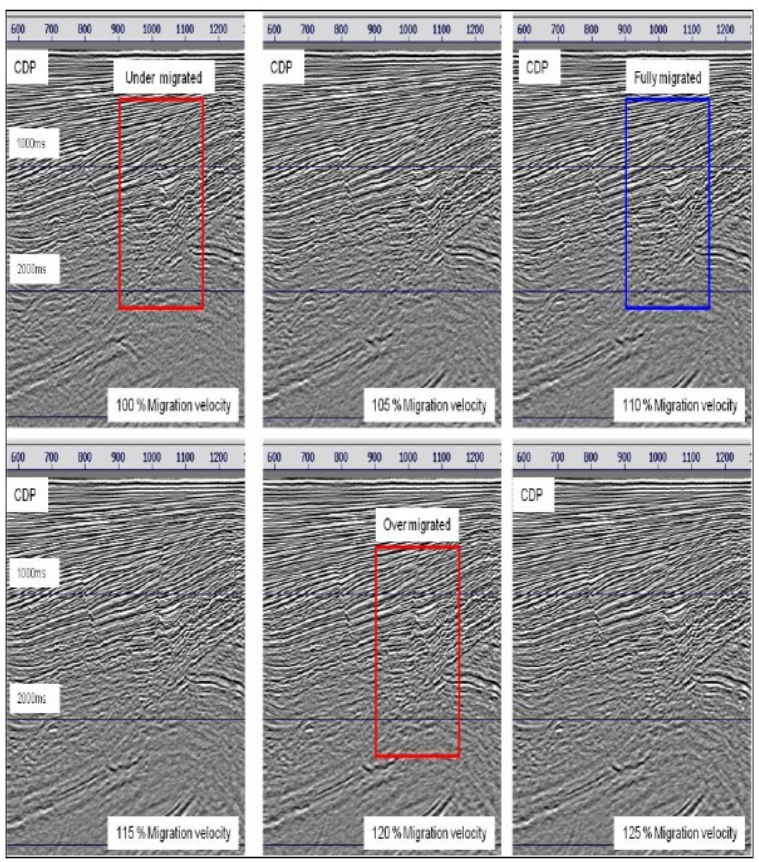

Figure 23:The comparison of velocity scaling of post-stack finite different migration test. $110 \%$ scaling shows a reasonable result of migration.

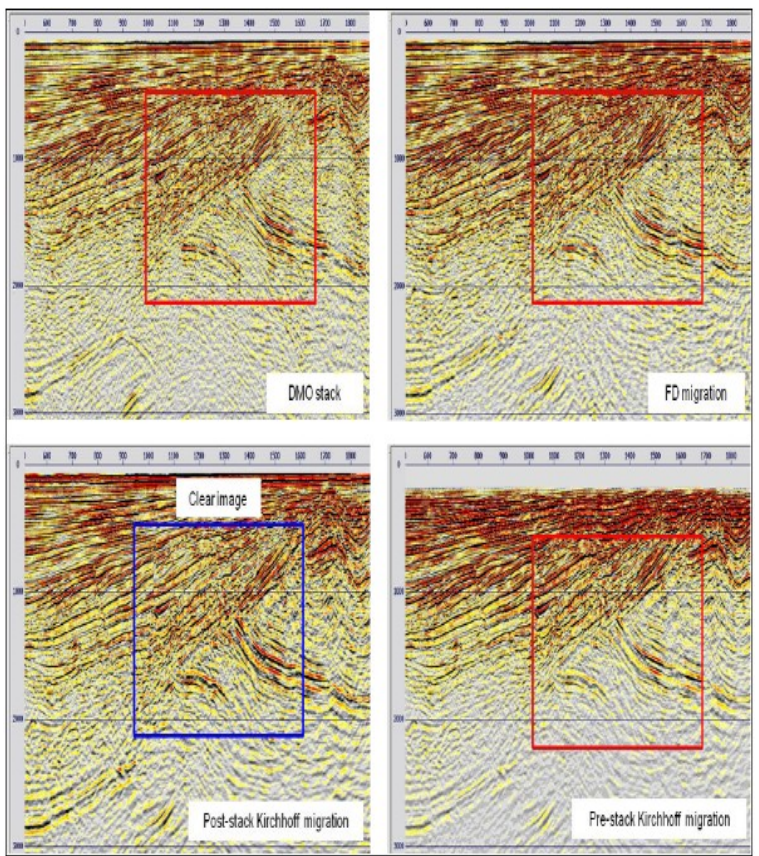

Figure 24:The result of post-stack Kirchoff migration provide better image at the edge of the thrust compare with the finite difference migration. 


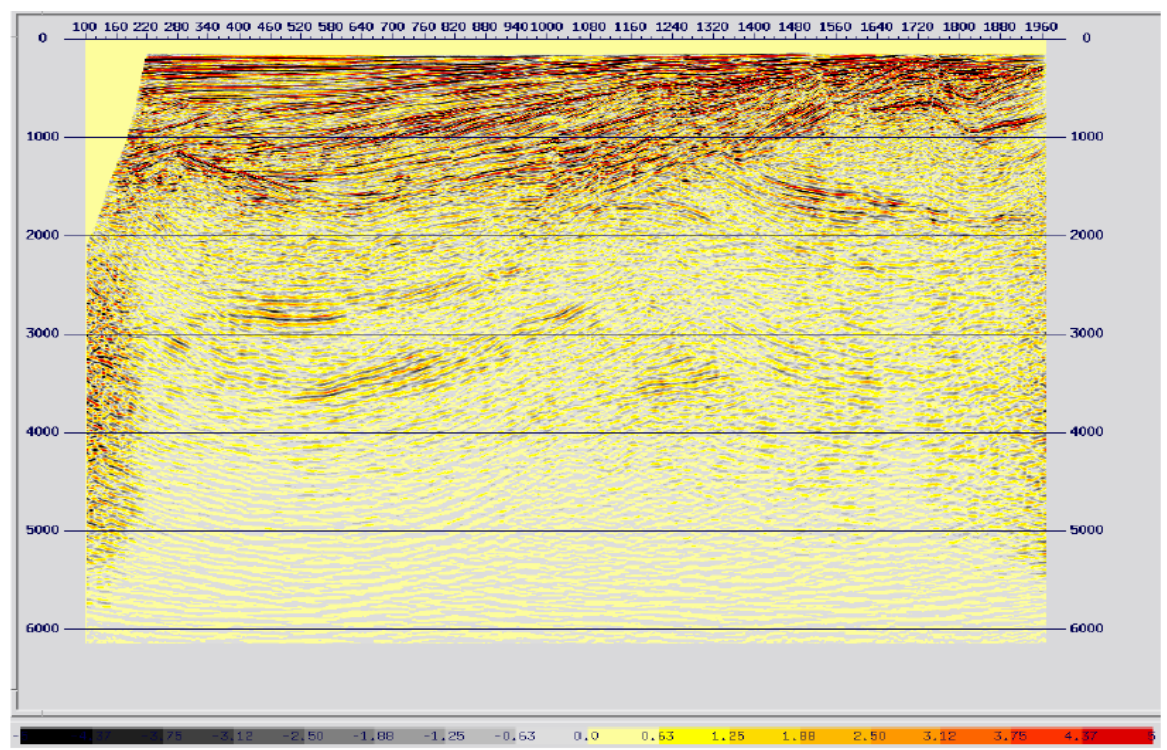

Figure 25: Kirchhoff Post-stack Migration

\section{Conclusions And Recommendations}

In terms of the geological point of view, the dataset was not complicated to re-process in the eastern part. This is owing to the fact that the velocity trend increase with depth as usual. In the western part where the Alpha thrust fault is located, the velocity trend is not increasing with depth; this is the reason why the conventional time imaging does not work well in this area. In the final re-processed section, the quality of the migrated section varies eastward to the west as shown in Figure 26. In Figure 26 when compared to the interpreted result with the published interpretation, we observe a well imaged result, faults in the upper section, the Alpha fault and the main reservoir interval are correctly imaged and well interpretable. The acquisition parameter of the line APH-434 is not sufficient for applying advanced processing method which is able to improve the final section. For instance, the maximum offset of the data is limited at $3233 \mathrm{~m}$ which is very short when compare with modern marine seismic acquisition. The offset parameter relates to an accuracy of velocity analysis, fold coverage and demultiple.

In the GlobeClaritas software, the simple module for swell noise attenuation is not available; therefore, the low cut filter was used to remove swell noise. In the APH-434 dataset, the frequency content of noise and data are the same. Thus, the processor has to make decision whether to preserve data or attenuate noise.

The recommendation to improve the processing result of this dataset is by ideally carrying out a prestack time migration by improving the velocity in the pre-stack time migration. Also the image produced is in time, it will be very useful if it is converted into depth. It would also be a good idea if other software such as ProMAXis used to process the APH-434 dataset.

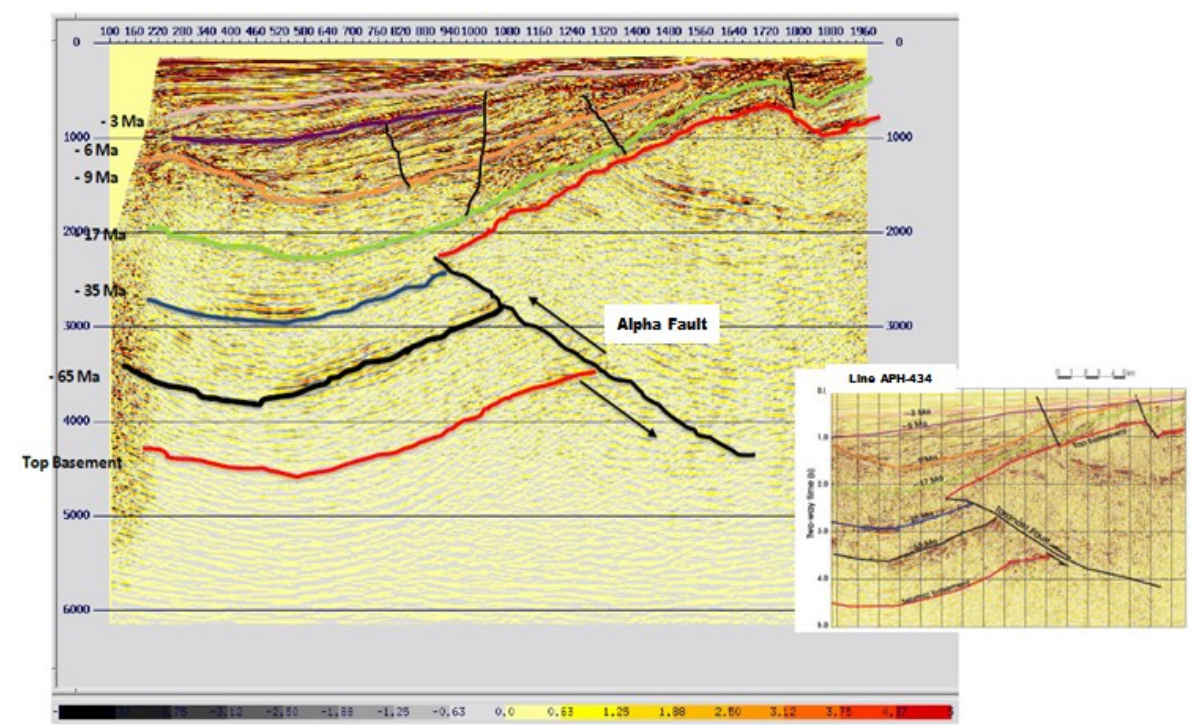

Figure 26:Interpreted final result compared to the published interpretation 


\section{References}

[1]. Gadallah M.R.,\& Fisher R.L., 2005. Applied Seismology: a comprehensive guide to seismic theory and application. 1st ed. Penwell books Corporation.

[2]. GNS Science, 2009. New Zealand`s Sedimentary Basins. Available at http://www.gns.cri.nz

[3]. Hatton, L., Worthington, M. H. \& Makin, J. (1986) Seismic data processing: theory and practice. Oxford, Blackwell Scientific

[4]. Holt, T. S. (2004). Subduction, plateform subsidence, and foreland thrust loading: The late Tertiary of Alpha basin, New Zealand. New Zealand Petroleum Conference, (pp. 1-9

[5]. Nicol, A., Stagpoole, V. M. \&Maslen, M. (2004) New Zealand. Structure and petroleum potential of the Alpha fault play. 2004 New Zealand Petroleum Conference Proceedings.

[6]. Russell, B. (1998). A simple seismic imaging exercise. The Leading Edge, 885-889.

[7]. Yilmaz, O. (2005). Seismic data analysis: processing, inversion, and interpretation of seismic data. Investigations in geophysics, 2nd edition. Tulsa, OK, Society of Exploration Geophysicists 